\title{
CO Gas Sensing Using Ga Doping ZnO Nanorods by Hydrothermal Method: Effects of Defects-Controlled
}

\author{
Duy-Thach Phan, Gwiy-Sang Chung* \\ School of Electrical Engineering, University of Ulsan, Republic of Korea \\ *gschung@ulsan.ac.kr
}

\begin{abstract}
We report here the synthesis Ga-doped ZnO nanorods by hydrothermal (HT) method and investigate the effects of Ga-doping on their $\mathrm{CO}$ sensing properties. It is found that $\mathrm{Ga}$ doping cancel out oxygen-related defects (oxygen interstitial) based on the results of photoluminescence (PL) experiments and further confirmed by the $\mathrm{CO}$ sensing experiment. The defect-controlled, which are donor-(shallow donor and zinc interstitial) and acceptor-related (oxygen interstitial) ones, in $\mathrm{ZnO}$ nanorods were adjusted by $\mathrm{Ga}$ doping level. The $\mathrm{CO}$ sensing properties of $\mathrm{ZnO}$ nanorods are effectively improved by Ga doping. These can be explained in term of the removal excess oxygen in $\mathrm{ZnO}$ nanorods surface, increase shallow donor concentration and Ga-doped $\mathrm{ZnO}$ formed active component for $\mathrm{CO}$ absorption.
\end{abstract}

Key words: $\mathrm{CO}$ gas sensing, Ga doping, $\mathrm{ZnO}$ nanorods, Hydrothermal method, Defects-controlled

\section{Introduction}

Carbon monoxide $(\mathrm{CO})$ is one of the most dangerous gases in air pollution and human life. $\mathrm{CO}$ is produced by incomplete combustion of fuels and commonly found in the emission of automobile exhaust, the burning of domestic fuels, etc. It is highly toxic and extremely dangerous because it is colorless and odorless [1]. Among several materials for $\mathrm{CO}$ sensing, $\mathrm{ZnO}$ nanostructures are considered as one of most potential candidates for gas sensor due to large specific surface area, good biocompatibility and high electron mobility [2]. Doping with other element is effective way in order to improve gas sensing properties of $\mathrm{ZnO}$ nano-structure at low temperature. For example, Han et al. [3] evaluated the doping effect of Fe, $\mathrm{Ti}$ and $\mathrm{Sn}$ on gas sensing property of $\mathrm{ZnO}$. Gaspera et al. [4] consider the effects of doping transition metal ions into $\mathrm{ZnO}$, resulting in a lower detection limit of $1-2 \mathrm{ppm} \mathrm{CO}$ at $300{ }^{\circ} \mathrm{C}$. However, the role of the dopants in the gas sensing process is however not well recognized, with presumption and discussion based on term of crystal structure, defects, surface area or active sensing component by doping.

The nonstoichiometry (crystal defects) of $\mathrm{ZnO}$ was a key factor determining the gas sensing properties [5-7]. These crystal defects such as oxygen vacancies [5-6] or shallow donor [7] play role as absorb site for gas molecules along $\mathrm{ZnO}$ nanostructures surface. The crystal defects can be controlled by doping [6] or postannealing process $[5,7]$. The $\mathrm{ZnO}$ nanostructures syntheses by physic vapor deposition (as vapor liquid solid or thermal evaporation) at high temperature usually possess oxygen vacancies defects [5-6] and inversely $\mathrm{ZnO}$ nanostructures synthesized by wet chemical method contain oxygen interstitial (excess oxygen) [7-9]. In comparison with physic vapor synthesis method, the chemical route, for example hydrothermal method has several advantages as low temperature, simple, cheap and easy for doping. Recently, Li et al. doped $\mathrm{Co}$ into $\mathrm{ZnO}$ nanorods to enhance $\mathrm{CO}$ sensing properties by electrochemical deposition, which is an economic, effective approach and suitable for large-scale production [9].

Among these metal dopants, the $\mathrm{Ga}$ doping seems to be the most successful and promising due to its advantages, such as the rather similar ionic radius and the covalent radius $(0.62$ and $1.26 \AA$ ), as compared to those of $\mathrm{Zn} \mathrm{(0.74} \mathrm{and}$ $1.34 \AA$ ), respectively. Therefore, the $\mathrm{Ga}^{3+}$ can be substituted for $\mathrm{Zn}^{2+}$ without any lattice distortion and cause free-stress in $\mathrm{ZnO}$ materials. For the doping $\mathrm{Ga}$ into $\mathrm{ZnO}$ nanostructure, some typical growth techniques were used, such as the hydrothermal method [10], thermal evaporation [11] and pulsed laser deposition [12]. Among them, the hydrothermal method has distinct advantages of a large area film at a low cost, excellent compositional control, homogeneity on the molecular level due 
to the mixing of liquid precursors, and lower crystallization temperature [10]. In this work, we describe the synthesis and characterization of Ga-doped ZnO nanorods by hydrothermal method and investigate the effects Ga-doping on $\mathrm{CO}$ sensing properties of $\mathrm{ZnO}$ materials.

\section{Experimental}

The vertically aligned $\mathrm{ZnO}$ nanorods grow on p-type silicon ( $\mathrm{Si}$ ) to form $\mathrm{p}$-n junction as a $\mathrm{CO}$ gas sensor. A template $\mathrm{ZnO}$ thin film was deposited as a seed layer on p-Si substrates by sol-gel technology before synthesizing the nanorods. The $\mathrm{ZnO}$ template, with a $200 \mathrm{~nm}$ thickness, was prepared by sol-gel method [13]. Next, ZnO nanorods were grown on $\mathrm{ZnO}$ seed layer coated $\mathrm{p}$-Si substrates by hydrothermal method, which are $100 \mathrm{ml}$ aqueous solution included $0.025 \mathrm{M}$ zinc nitrate hexahydrate $\left(\mathrm{Zn}\left(\mathrm{NO}_{3}\right)_{2} \cdot 6 \mathrm{H}_{2} \mathrm{O}\right)$ and $0.025 \mathrm{M}$ hexamethylenetetramine $\left(\mathrm{C}_{6} \mathrm{H}_{12} \mathrm{~N}_{4}\right)$ in sealed Teflon lined autoclave. To prepare the Ga-doped $\mathrm{ZnO}$ nanorods array, $\mathrm{Ga}$ concentration in the solution was varied from 0 at. $\%$ to 4 at. $\%$. In detail, the different amounts of gallium nitride $\left(\mathrm{Ga}\left(\mathrm{NO}_{3}\right)_{3} . \mathrm{xH}_{2} \mathrm{O}, \quad 99.9 \%\right.$. Aldrich) were dissolved in a solution of zinc nitride hexahydrate and hexamethylenetetramine to fix its concentration at $0,0.0125,0.025,0.05,0.075$ and $0.1 \mathrm{mM}$ for undop, dop $0.5 \%$ to $4 \% \mathrm{Ga}$, respectively. The autoclave was kept in a laboratory oven at a constant temperature of $90{ }^{\circ} \mathrm{C}$ for $4 \mathrm{~h}$.

The front contacts were deposited with gold $\mathrm{Au}$ ) on the top $\mathrm{ZnO}$ nanorods via metal mask using RF sputtering. The diameter of the contact was $1 \mathrm{~mm}$. Ohmic contact was also made using thermal evaporator by depositing aluminum (Al) on the back of $\mathrm{p}$-Si substrate. The ohmic contact was achieved by vacuum annealing structures at $400{ }^{\circ} \mathrm{C}$ for $3 \mathrm{~min}$. The p-n junction samples with undop and Ga-doped $\mathrm{ZnO}$ nanorods grown on $\mathrm{p}$-Si were assigned number from 1 to 6 as in Fig. 1. The crosssectional structures of the n-type Ga:ZnO nanorods/ZnO seed layer/p-Si heterojunction for $\mathrm{CO}$ gas sensor was showed as Fig. 1. The $\mathrm{I}-\mathrm{V}$ characteristics of the Au/n-ZnO/p-Si/Al diode were performed with KEITHLEY 4200 semiconductor characterization system. The surfaces of the thin films were characterized using a JSM-6500F field emission scanning electron microscope (FE-SEM). At.\% (Atomic percent) of gallium in $\mathrm{ZnO}$ nanorods after synthesis was characterized by EDS (energy dispersive spectroscopy) equipped to FE-SEM. For optical characterization, photoluminescence (PL) measurements were obtained using a He$\mathrm{Cd}$ laser operating at a wavelength of $325 \mathrm{~nm}$ and an excitation power of $15 \mathrm{~mW}$.

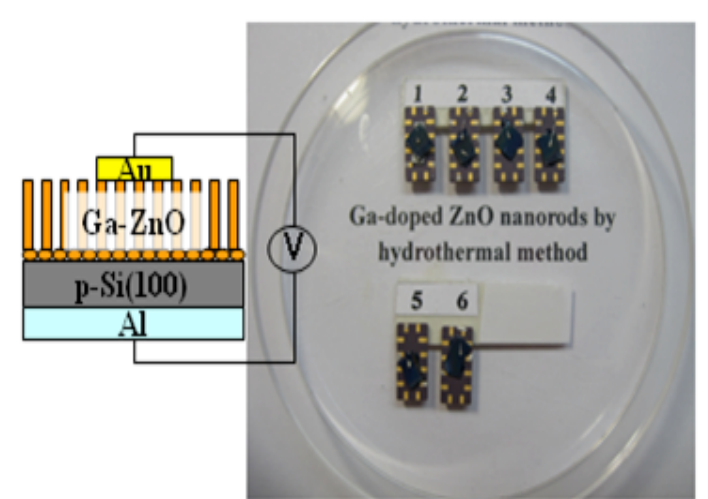

Fig. 1. The cross-sectional structures of the n-type Ga:ZnO nanorods/p-Si heterojunction (Sample 1 to 6 for undop, dop $0.5 \%, 1 \%$, 2\%, 3\% and $4 \% \mathrm{Ga:ZnO)}$.

\section{Results and Discussion}

Fig. 2 (a) shows SEM images (top-view) of $\mathrm{ZnO}$ nanorods grown on $\mathrm{p}$-Si substrate. The $\mathrm{ZnO}$ nanorods formed uniform rods in large area with average length is $750 \mathrm{~nm}$ (cross-view not show) and $100 \mathrm{~nm}$ in diameter. Fig. 2(a) show Ga-doping effects on $\mathrm{ZnO}$ nanorods morphology growth by hydrothermal method. In general, $\mathrm{ZnO}$ nanorods diameter became smaller with increasing doping concentration. At $2 \%$ Ga-doping, the $\mathrm{ZnO}$ nanorods diameter is the smallest and is more uniform rods in large area. When increasing to $3 \% \mathrm{Ga}$ doping, $\mathrm{ZnO}$ nanoseeds appeared and mixed up with $\mathrm{ZnO}$ nanorods, which can be explained as large distortion and are affected on natural growth behavior of $\mathrm{ZnO}$ nanorods array. At $4 \% \mathrm{Ga}-$ doping, the $\mathrm{ZnO}$ nanorods array were replaced by dense $\mathrm{ZnO}$ film comprise a lot of $\mathrm{ZnO}$ nanoseeds. The doped concentration was measured by EDS as shown in Fig. 2 (b) of 1 at.\% Ga-doped $\mathrm{ZnO}$. The table inserted in the figure shows the relationship between $\mathrm{Ga}$ concentrations in the solution an nanorods. Gallium ions in the precursor solution seem to be will incorporated into $\mathrm{ZnO}$ nanorods until 3\% doping.

Fig. 3 shows the PL spectra of $\mathrm{ZnO}$ nanorods at room temperature growth by hydrothermal method with various Ga-doping concentrations consist of a UV emission at wavelength of 380 $\mathrm{nm}$ and a broad green emission band at $580 \mathrm{~nm}$. The strong UV emission, which strongly relate to crystallite quality of $\mathrm{ZnO}$, was contribute by conduction-valence band combination ( $375 \mathrm{~nm})$, shallow donor $(\sim 395 \mathrm{~nm})$ and $\mathrm{Zn}$ interstitial $(\sim 420 \mathrm{~nm})$ [5-7]. Fig. 3 shows an enhancement UV emission following to increase Ga-doping until $2 \%$ concentration. By doping suitable amount of $\mathrm{Ga}$, the $\mathrm{Ga}$ atoms occupied at $\mathrm{Zn}$ vacancies defect position and increased donorrelated defects (such as shallow donor and zinc interstitial) quantities in $\mathrm{ZnO}$ nanorods leading to strong UV emission in PL spectra [14]. With over 
doping, Ga atoms go into lattice sites substituting for $\mathrm{Zn}$ atom caused serious lattice distortion and leading to decrease UV emission peak at $3 \%$ and $4 \%$. Especially, the broad green emission peak at $580 \mathrm{~nm}$, which mainly contributed by oxygen rich in hydrothermal method [8], was disappeared by Ga-doping concentration higher $1 \%$. This phenomenon needed further study for fully explanation.
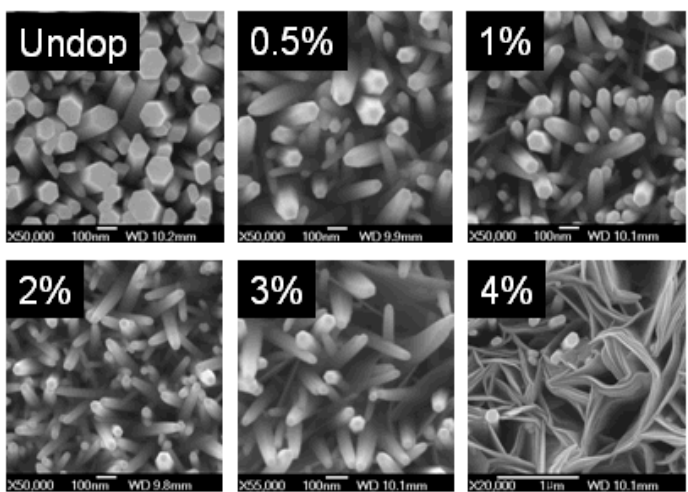

(a)

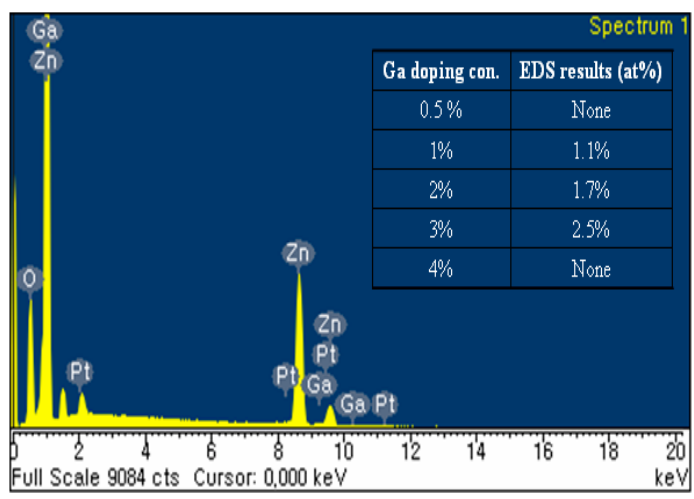

(b)

Fig. 2. Effects of Ga-doping on (a) ZnO nanorods morphology and (b) EDS spectra of at. $1 \% \mathrm{Ga}$ doped $\mathrm{ZnO}$ nanorods.

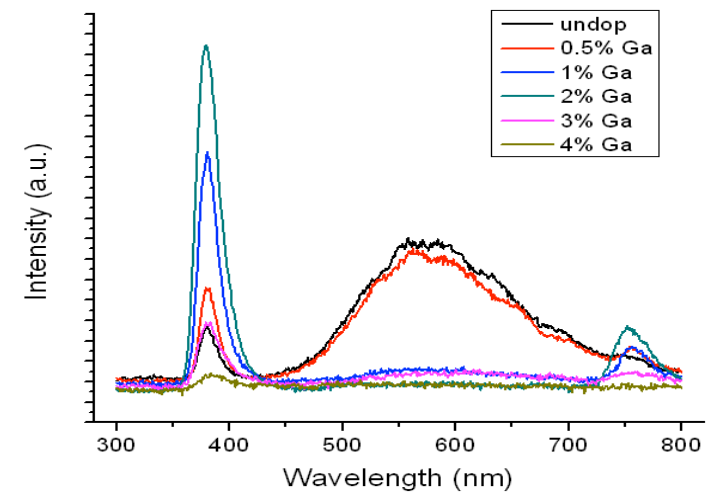

Fig. 3. PL spectra of Ga-doped $\mathrm{ZnO}$ nanorods.

Fig. 4 (a) shows linear response of Ga-doped $\mathrm{ZnO}$ nanorods at $75{ }^{\circ} \mathrm{C}$ with various $\mathrm{CO}$ concentrations, the increasing $\mathrm{Ga}$ concentration in $\mathrm{ZnO}$ nanorods yield more sensitivity with $\mathrm{CO}$ gas and obtained optimal doping value for $\mathrm{CO}$ gas sensing at $2 \%$. Fig. 4 (b) shows repeatability of $\mathrm{CO}$ gas sensors at $1000 \mathrm{ppm}$ concentration, the maximum sensitivity $S$ is $25 \%$ for $2 \%$ Ga-doping sample. The response time and recovery time $\left(\tau_{90}\right)$ of sensor are 11 seconds and 21 seconds, respectively. The CO plays role as a reductive gas behavior with $n$ type semiconductor $\mathrm{ZnO}$ materials [2]. The reducing gas reacts with chemisorbed oxygen $\left(\mathrm{O}^{-}\right)$on $\mathrm{ZnO}$ nanorods surface and released free electron back to conduction band $\left(\mathrm{CO}+\mathrm{O}^{-}\right.$ $\rightarrow \mathrm{CO}_{2}+\mathrm{e}^{-}$); hence increased conductivity in $\mathrm{ZnO}$ nanorods. The high sensitivity in $\mathrm{Ga}-$ doping $\mathrm{ZnO}$ nanorods samples may be related to increasing donor-related (shallow donor) defects, reducing acceptor-related defects (oxygen interstitial) [5-7] and Ga:ZnO play role as active component for $\mathrm{CO}$ sensing [12].

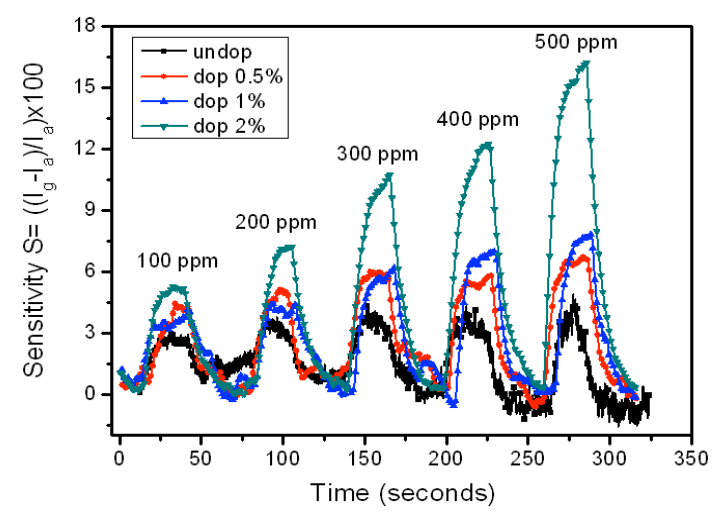

(a)

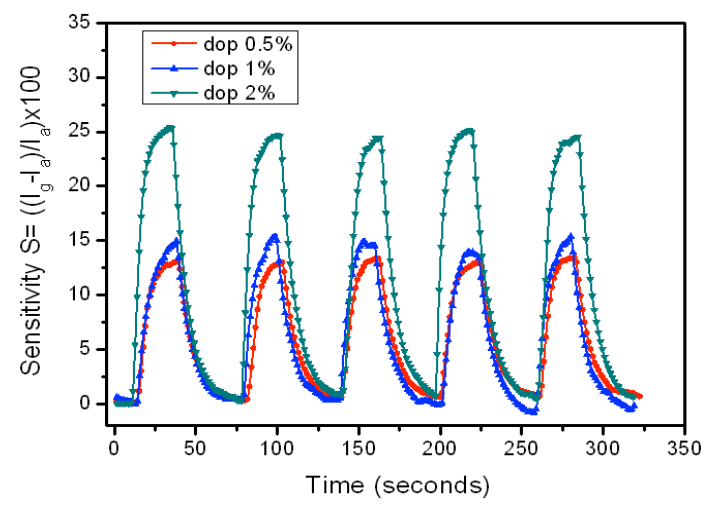

(b)

Fig. 4. Current response of Ga:ZnO nanorods/p-Si as $p$-n junction for (a) various concentration $\mathrm{CO}$ and (b) repeatability in $1000 \mathrm{ppm} \mathrm{CO}$ at $75^{\circ} \mathrm{C}$, fixed bias of $2 \mathrm{~V}$.

\section{Conclusions}

We illustrated Ga-doping into $\mathrm{ZnO}$ nanorods by hydrothermal method and investigate their $\mathrm{CO}$ gas sensing properties. We found that $\mathrm{Ga}$ atoms can be replaced $\mathrm{Zn}$ atoms without serious distortion until $2 \%$. The Ga-doping $\mathrm{ZnO}$ nanorods at suitable doping concentration can improve conductivity, optical properties and 
cancel out acceptor-related defects (oxygen interstitial). Resulting in $\mathrm{Ga}: \mathrm{ZnO}$ enhanced $\mathrm{CO}$ sensing property compare to pure $\mathrm{ZnO}$ nanorods. The $\mathrm{CO}$ gas sensing based $p-n$ junctions have good response with sensitivity up to $25 \%$ in $1000 \mathrm{ppm} \mathrm{CO}$ at $75{ }^{\circ} \mathrm{C}$ with response time of few ten seconds.

\section{Acknowledgement}

This research was supported by the Korea $\mathrm{R}$ esearch Foundation Grant through the Human Resource Training Project for Regional Innovati on funded by 2011 the Korean Government whi ch was conducted by the Ministry of Education, Science and Technology.

\section{References}

[1] H. Gong, J.Q. Hu, J.H. Wang, C.H. Ong, F.R. Zhu, Nano-crystalline Cu-doped $\mathrm{ZnO}$ thin film gas sensor for CO, Sensors and Actuators B: Chemical 115, 247-251 (2006); doi: 10.1016/ j.snb.2005.09.008

[2] A. Wei, L. Pan, W. Huang, Recent progress in the $\mathrm{ZnO}$ nanostructure-based sensors, Materials Science and Engineering: B 176, 1409-1421 (2011); doi: 10.1016/j.mseb.2011.09.005

[3] N. Han, L. Chai, Q. Wang, Y. Tian, P. Deng, Y. Chen, Evaluating the doping effect of $\mathrm{Fe}, \mathrm{Ti}$ and Sn on gas sensing property of $\mathrm{ZnO}$, Sensors and Actuators B: Chemical 147, 525-530 (2010); doi: 10.1016/j.snb.2010.03.082

[4] E. Della Gaspera, M. Guglielmi, G. Perotto, S. Agnoli, G. Granozzi, M.L. Post, A. Martucci, CO optical sensing properties of nanocrystalline $\mathrm{ZnO}-\mathrm{Au}$ films: Effect of doping with transition metal ions, Sensors and Actuators B: Chemical 161, 675-683 (2012); doi: 10.1016/j.snb.2011. 11.011

[5] M.W. Ahn, K.S. Park, J.H. Heo, J.G. Park, D.W. Kim, K.J. Choi, J.H. Lee, S.H. Hong, Gas sensing properties of defect-controlled $\mathrm{ZnO}$-nanowire gas sensor, Applied Physics Letters 93, 263103(1)263103(3) (2008); doi: 10.1063/1.3046726
[6] L.M. Li, Z.F. Du, T.H. Wang, Enhanced sensing properties of defect-controlled $\mathrm{ZnO}$ nano tetrapods arising from aluminum doping, Sensors and Actuators B: Chemical 147, 165-169 (2010); doi: 10.1016/j.snb.2009.12.058

[7] N. Han, X. Wu, L. Chai, H. Liu, Y. Chen, Counterintuitive sensing mechanism of $\mathrm{ZnO}$ nanoparticle based gas sensors, Sensors and Actuators B: Chemical 150, 230-238 (2010); doi: 10.1016/j.snb.2010.07.009

[8] C. Chandrinou, N. Boukos, C. Stogios, A. Travlos, PL study of oxygen defect formation in $\mathrm{ZnO}$ nanorods, Microelectronics Journal 40, 296298 (2009); doi: 10.1016/j.mejo.2008.07.024

[9] Y.J. Li, K.M. Li, C.Y. Wang, C.I. Kuo, L.J. Chen, Low-temperature electrodeposited Co-doped $\mathrm{ZnO}$ nanorods with enhanced ethanol and $\mathrm{CO}$ sensing properties, Sensors and Actuators B: Chemical 161, 734-739 (2012); doi: 10.1016/ j.snb.2011.11.024

[10] H. Wang, S. Baek, J. Song, J. Lee, S. Lim, Microstructural and optical characteristics of solution-grown Ga-doped ZnO nanorod arrays, Nanotechnology 19, 075607 (2008); doi: 10.1088/ 0957-4484/19/7/075607

[11] C.H. Ahn, W.S. Han, B.H. Kong, H.K. Cho, Gadoped $\mathrm{ZnO}$ nanorod arrays grown by thermal evaporation and their electrical behavior, Nanotechnology 20,015601(1)-015601(7) (2009); doi: 10.1088/ 0957-4484/20/1/015601

[12] K. Kim, Y.W. Song, S. Chang, I.H. Kim, S. Kim, S.Y. Lee, Fabrication and characterization of Gadoped $\mathrm{ZnO}$ nanowire gas sensor for the detection of CO, Thin Solid Films 518, 1190-1193 (2009); doi: 10.1016/j.tsf.2009.03.229

[13] D.T. Phan, G.S. Chung, Comparison of $\mathrm{ZnO}$ thin films grown on a polycrystalline $3 \mathrm{C}-\mathrm{SiC}$ buffer layer by RF magnetron sputtering and a sol-gel method, Applied Surface Science 257, 32853290 (2011); doi: 10.1016/j.apsusc.2010.11.003

[14] L. Xu, F. Gu, J. Su, Y. Chen, X. Li, X. Wang, The evolution behavior of structures and photo luminescence of $\mathrm{K}$-doped $\mathrm{ZnO}$ thin films under different annealing temperatures, Journal of Alloys and Compounds 509, 2942-2947 (2011); doi: 10.1016/j.jallcom.2010.11.164 